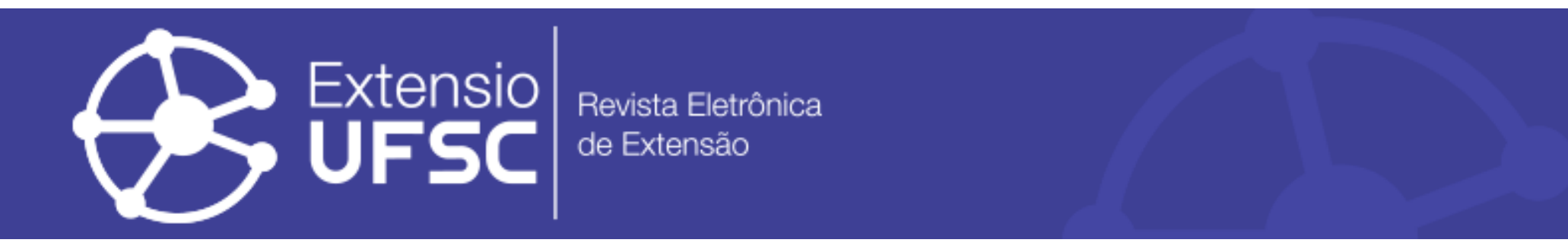

\title{
PREVENÇÃO DE CÁRIE EM CRIANÇAS DO PIAUÍ: UM RELATO DE EXPERIÊNCIA
}

\author{
Valéria Silva Sena \\ Universidade Estadual do Piauí \\ senna.valeria@gmail.com \\ Carlos Alberto Monteiro Falcão \\ Universidade Estadual do Piauí \\ falcaoendo@hotmail.com \\ Hilva Stella de Araújo Batista \\ Universidade Estadual do Piauí \\ stella.odonto@hotmail.com
}

\author{
Hudson Oliveira Silva \\ Universidade Estadual do Piauí \\ hudsonphb@gmail.com \\ Raphael Machado Primo \\ Universidade Estadual do Piauí \\ raphael_primo@live.com \\ Maria Ângela Arêa Leão Ferraz \\ Universidade Estadual do Piauí \\ angela.endo@hotmail.com
}

\begin{abstract}
Resumo
A articulação ensino, pesquisa e extensão é pilar do Ensino Superior, pois possibilita a troca de experiências entre a sociedade e comunidade acadêmica. O curso de Odontologia da Universidade Estadual do Piauí (UESPI) realizou o "Projeto de Extensão - UESPI ODONTO: prevenção de cárie em crianças atendidas nas creches do projeto social da Diocese de Parnaíba-PI". Como proposta de transmissão de conhecimentos foram realizadas atividades lúdicas como palestras educativas, doação de escovas dentais e a realização de ações de prevenção como escovação supervisionada, evidenciação de placa bacteriana e aplicação tópica de flúor. Destacou-se o encaminhamento de crianças com necessidades específicas para atendimento na Clínica Escola de Odontologia da UESPI/Parnaíba. O projeto buscou integrar os estudantes de Odontologia à sociedade, modificando realidades e melhorando a qualidade de vida das populações assistidas, redefinindo, assim o papel da UESPI no desenvolvimento da região.

Palavras-chave: Odontologia .Relações Comunidade-Instituição. Assistência Odontológica para Crianças.

\section{PREVENTION OF CARIES IN CHILDREN OF PIAUÍ: A REPORT OF EXPERIENCE}

\begin{abstract}
The articulation of teaching, research and extension is a pillar of Higher Education, as it enables the exchange of experiences between society and the academic community. The Dentistry course of the State University of Piauí (UESPI) carried out the "Extension Project - UESPI ODONTO: prevention of caries in children attending daycare centers of the social project of the Diocese of Parnaíba-PI". As a proposal for the transmission of knowledge, ludic activities were carried out, such as educational lectures, donation of toothbrushes and preventive actions such as supervised brushing, evidence of bacterial plaque and topical application of fluoride. It was highlighted the referral of children with specific needs to attend the Clinical School of Dentistry of UESPI/Parnaíba. The project sought to integrate dentistry students into society, modifying realities and improving the quality of life of the assisted populations, thus redefining the role of UESPI in the development of the region.
\end{abstract}

Keywords: Dentistry. Community-Institution Relations.Dental Care for Children.

\section{PREVENCIÓN DEL CARIES EN NIÑOS DE PIAUÍ: UN INFORME DE EXPERIENCIA}

\section{Resumen}

La articulación enseñanza, investigación y extensión es pilar de la Enseñanza Superior, pues posibilita el intercambio de experiencias entre la sociedad y la comunidad académica. El curso de Odontología de la Universidad Estadual de Piauí (UESPI) realizó el "Proyecto de Extensión - UESPI ODONTO: prevención de caries en niños atendidos en las guarderías del proyecto social de la Diócesis de Parnaíba-PI". Como propuesta de transmisión de conocimientos se realizaron actividades lúdicas como charlas educativas, donación de cepillos dentales y la realización de acciones de prevención como cepillado supervisado, evidencia de placa bacteriana y aplicación tópica de flúor. Se destacó el encaminamiento de niños con necesidades específicas para atención en la Clínica Escuela de Odontología de la UESPI / Parnaíba. El proyecto buscó integrar a los estudiantes de Odontología a la sociedad, modificando realidades y mejorando la calidad de vida de las poblaciones asistidas, redefiniendo, así el papel de la UESPI en el desarrollo de la región.

Palavras clave: Odontología. Relaciones Comunidad-Institución. Atención Dental para Niños. 
Prevenção de cárie em crianças do Piauí: um relato de experiência

\section{INTRODUÇÃO}

A extensão universitária é um dos pilares da formação acadêmica, sendo esta, sob o princípio constitucional da indissociabilidade entre ensino, pesquisa e extensão definida como "um processo interdisciplinar, educativo, cultural, científico e político, capaz de promover a interação transformadora entre Universidade e outros setores da sociedade"(FORPROEX, 2012, p. 15). A atenção à saúde deve objetivar a integralidade e deve ser planejado e elaborado de maneira interprofissional, a fim de promover a valorização dos usuários de acordo com suas necessidades.

Nesse contexto, verifica-se que a extensão universitária corresponde às ações sociais da Universidade, onde essas ações apresentam-se para a sociedade como um meio de aplicação dos conteúdos aprendidos na universidade para o ensino e pesquisa(MENDONÇAet al 2013), além de humanizar o futuro profissional ainda no decorrer da formação (PEREIRA et al 2013) por permitir a vivência extramuros, e, diferentemente da realidade nas clínicas e salas de aula, a prática extensionista se sobressai como um instrumento importante no desenvolvimento social do acadêmico (MEDEIROS et al 2014)

O trabalho de extensão universitária é uma experiência fundamental para a formação profissional do acadêmico, sendo um meio de crescimento pessoal que possibilita a sua inserção precoce nos problemas sociais da comunidade. Ele pretende ultrapassar a vivência diária nas clínicas odontológicas curriculares e trabalhar intensamente, no decorrer das atividades de extensão, o lado humanista do acadêmico, então, associando o conhecimento teórico e a experiência pessoal para a formação em cirurgião-dentista. Dessa maneira, espera-se um amadurecimento do aluno, influenciando de forma positiva em sua profissão, isto é, mediante a sua participação nessas práticas extensionistas se tem a chance de entender melhor o que está por vir e consequentemente se preparar para que sua atividade seja efetiva tanto para ele quanto para quem irá usufruir do seu serviço profissional (MORAESet al 2016).

Nesse sentido, deve-se propiciar aos graduandos a possibilidade de experimentar e intervir na realidade, por meio da extensão universitária, pois essas ações contribuirão para o desenvolvimento da sua formação profissional moldada de forma crítica-reflexiva, valorizando a interdisciplinaridade e os aspectos humanos, como também a consolidação de serviços de saúde que resolvam as necessidades da população (BISCARDE,PEREIRA-SANTOS e SILVA, 2014).

Além dos benefícios à formação profissional dos acadêmicos, a vivência extensionista proporciona a prestação de serviços assistenciais à comunidade(RODRIGUES et al 2013) e 
Prevenção de cárie em crianças do Piauí: um relato de experiência

possibilita à população carente o acesso a informações sobre saúde de forma gratuita e de qualidade (PEREIRAet al 2011).

Essa interação universidade-comunidade é parte constituinte do processo educativo, cultural e científico, que torna indissociável a articulação ensino e pesquisa e tende a contribuir para formar um profissional que se compromete com a realidade social que o cerca (WARMLING, 2012)(DENECI, 2014).

Desse modo, pode-se inferir que a extensão universitária é de importância para os três atores nela envolvidos: universidade, acadêmicos e sociedade. Nesse contexto, a universidade ganha mais credibilidade em meio à sociedade, o aluno adquire mais conhecimento e capacitação profissional, e a sociedade recebe benefícios através das práticas assistenciais (RODRIGUES et an2013).

Nessa perspectiva, este relato de experiência enfatiza a importância da extensão universitária para formação acadêmica de profissionais comprometidos com a realidade social. Este trabalho tem o objetivo de relatar a experiência do "Projeto de Extensão - UESPI ODONTO: prevenção de cárie em crianças atendidas nas creches do projeto social da Diocese de Parnaíba-PI", do Curso de Odontologia da Universidade Estadual do Piauí (UESPI).

\section{MATERIAIS E MÉTODOS}

O presente artigo trata-se de um relato de experiência de caráter descritivo do "Projeto de Extensão - UESPI ODONTO”, desenvolvido semanalmente, nos semestres 2015.2 a 2017.1, envolvendo 220 crianças.

O projeto é vinculado ao Projeto Social da Diocese de Parnaíba, cidade localizada a 338 quilômetros da capital Teresina - Piauí, através do Convênio de concessão de estágio UESPI número 47/2015.

Para desenvolver o projeto foram selecionados vinte e um acadêmicos regularmente matriculados no curso de Odontologia da Universidade Estadual do Piauí (UESPI). A fim de cumprir os objetivos propostos pelo projeto, os acadêmicos foram divididos em sete grupos, possibilitando a execução das atividades nas sete creches vinculadas ao Projeto Social da Diocese de Parnaíba - Dom Rufino, Nossa Senhora das Mercês, Madre Cecília, São Francisco, São Leopoldo, Santa Teresinha, São Cláudio.

O principal objetivo do projeto foi a prevenção de cárie nas crianças que são assistidas nas creches. Essa proposta surgiu a partir da necessidade de transmissão de conhecimentos de 
Prevenção de cárie em crianças do Piauí: um relato de experiência

saúde bucal para as crianças, com a finalidade de conscientização e mudança de hábitos, visando a diminuição da incidência da doença cárie.

Como proposta de transmissão de conhecimentos, semanalmente foram realizadas atividades lúdicas como palestras educativas para as crianças abordando temas como: saúde bucal; cárie e placa bacteriana; hábitos alimentares e sua relação com cárie; hábitos de higiene escovação, uso do fio dental; flúor; hábitos indesejáveis (sucção chupetas, mamadeiras e dedo); e trauma dental,foram utilizados diferentes instrumentos educativos, como por exemplo: músicas, vídeos, fantoches, cartazes, macromodelos, macroescovas, desenhos e jogos.Durante as palestras as crianças foram orientadas: quanto a forma correta de se escovar os dentes e usar o fio dental havendo a demonstração em macromodelos de arcadas dentárias; quanto a cárie - sobre a sua etiologia, desenvolvimento e formas de prevenção; quanto a relação entre os alimentos e a cárie, e a necessidade de uma alimentação saudável.

As crianças foram avaliadas clinicamente para traçar o perfil de saúde bucal, e avaliar a necessidade de tratamento odontológico. Desta forma, foram realizados exames clínicos intrabucais na própria creche, com auxílio de espátula de madeira e sob luz natural. Os dados do exame clínico foram transcritos para ficha clínica adaptada para as atividades do projeto de extensão e aquelas crianças que foram diagnosticadas com problemas bucais passaram então a receber tratamento curativo junto à clínica escola de odontologia da UESPI.

As palestras educativas também foram realizadas com os pais e/ou responsáveis, coordenadores e voluntários da creche, bimestralmente, onde se buscou apresentar, para os mesmos, as atividades realizadas com as crianças, e ainda a transmissão de conhecimentos de saúde bucal.

Com a identificação da carência de escovas para as crianças nas creches, efetuou-se a doação para todas as crianças de kits de higiene dental - escova, creme dental e fio dental - , juntamente com porta-escovas (confeccionados pelos acadêmicos do projeto), para armazenagem de maneira eficaz e higiênica.

O projeto também contemplou a realização de ações de prevenção como escovação supervisionada semanalmente, com anterior evidenciação de placa bacteriana, com o intuito de estimular nas crianças a prática dos hábitos de higiene oral e manutenção da saúde bucal. A solução evidenciadora de placa bacteriana a base de fucsina básica foi aplicada nas superfícies dentais com auxílio de hastes de algodão, com objetivo de corar as áreas com placa. Este método favorece a instrução de higiene bucal ao tornar visível a placa, possibilitando o apontamento de locais onde a higienização encontrava-se deficiente para incentivar o hábito da boa escovação. 
Prevenção de cárie em crianças do Piauí: um relato de experiência

Destaca-se, ainda, a realização de triagem odontológicarealizada pelos acadêmicos, previamente calibrados. Estas triagens foram realizadas semestralmente no ambiente próprio de cada Creche participante para identificação de agravos de saúde bucal como cárie e má oclusãocomconsequente encaminhamento das crianças com necessidades identificadas para atendimento nas Clínicas de Odontopediatria da Clínica Escola de Odontologia da UESPI/Parnaíba.

\section{RESULTADOS E ANÁLISES}

A experiência adquirida com o "Projeto de Extensão - UESPI ODONTO" foi considerada satisfatória pelos acadêmicos e possibilitou enquanto graduandos em odontologia uma formação diferenciada, proporcionando aos acadêmicos envolvidos um aprimoramento científico, técnico e humano. Como também uma melhora na qualidade de vida das crianças, por meio da prevenção das doenças bucais e recuperação da saúde.

Durante os dois anos de execução do projeto observou-se aceitação da proposta pelas 220 crianças assistidas. Estas participaram de forma atuante nas atividades desenvolvidas, com relatos de ação como multiplicadores, em suas famílias, sobre atenção à saúde bucal e maior controle nas atividades de prevenção da cárie como a escovação, uso do fio dental e controle da dieta cariogênica.

Maders e Santos (2010) destacaram que estratégias de prevenção em saúde bucal direcionadas às crianças possuem resultados satisfatórios pelo fato das mesmas serem capazes adquirir conhecimentos e coloca-los em prática, contribuindo para que posteriormente essas crianças tenham qualidade na saúde bucal e geral.

Nas palestras com os pais, buscou-se enfatizar os cuidados com a saúde bucal das crianças desde o nascimento, destacando-se a responsabilidade que os pais possuem no cuidado e na manutenção da saúde bucal de seus filhos. A maior participação foi das mães, com participação mais efetiva à medida que projeto se consolidava, na roda de conversas destacavam sempre a mudança de postura de seus filhos sobre a saúde bucal. Segundo Valarelliet al. (2011), as palestras com os pais têm a função de ajudá-los a educarem seus filhos com atenção crescimento e desenvolvimento de um ser humano saudável, consciente do funcionamento do seu corpo, proporcionando seu bem-estar físico.

O desenvolvimento da escovação supervisionada com as crianças é um importante meio para manutenção da saúde bucal visto que "escovar os dentes é fundamental para prevenir a cárie, pois desorganiza a placa cariogênica, impedindo o processo de 
Prevenção de cárie em crianças do Piauí: um relato de experiência

desmineralização"(MACEDO, 2010).Nesse sentido, a escovação supervisionada, como atividade preventiva, foi realizada com o intuito de educar e também minimizar os efeitos da cárie sobre os dentes das crianças. A intervenção era executada após o término da refeição com supervisão dos acadêmicos.

Os voluntários das creches foram orientados para que as escovas fossem mantidas na instituição, para que a prática da escovação fosse mantida após a refeição durante os outros dias da semana, visto que as crianças passavam praticamente um turno do dia nas creches e a prática constante incentivaria a manutenção do hábito de higiene bucal.

\section{CONSIDERAÇÕES FINAIS}

O projeto buscou integrar os estudantes de Odontologia à comunidade na qual está inserida, conceitos e aprendizados adquiridos no meio acadêmico foram repassados às crianças, pais e responsáveis, de forma a socializar e democratizar o conhecimento, constituindo, assim, uma ponte permanente entre a universidade e a sociedade.

\section{REFERÊNCIAS}

BISCARDE, Daniela Gomes dos Santos; PEREIRA-SANTOS, Marcos; SILVA, Lília Bittencourt. Formação em saúde, extensão universitária e Sistema Único de Saúde (SUS): conexões necessárias entre conhecimento e intervenção centradas na realidade e repercussões no processo formativo. Interface-Comunicação, Saúde, Educação, v. 18, n. 48, p. 177-186, 2014.

DENECI, Verônica et al. O significado da participação em visitas domiciliares pelo acadêmico de odontologia. Revista da ABENO, v. 14, n. 1, p. 66-72, 2014.

FORPROEX, Fórum de Pró-Reitores de Extensão das Universidades Públicas Brasileiras. Política Nacional de Extensão Universitária. Manaus-AM; 2012. Disponível em<http://www.utfpr.edu.br/estrutura-universitaria/pro-reitorias/prorec/diretoria-deextensao/documentos-da-extensao-de-ambito-nacional/politica-nacional-de-extensaouniversitaria-forproex-2012/at_download/file>.Acesso em: 05 dez. 2016.

MACEDO, Cristiane Rufino. Cuidados gerais e higiene oral para prevenção de cáries em crianças. Diagn tratamento, v. 15, n. 4, p. 191-3, 2010.

MADERS, Caroline; SANTOS, Nathália Maria Lopes dos. O impacto do programa preventivoeducativo da Unidade de Saúde da Família Viçosa na saúde bucal de escolares. Revista da Faculdade de Odontologia de Porto Alegre, v 51, n 1, p 15-19, 2010.

MEDEIROS, Ana Lucia de França et al. A extensão universitária enquanto espaço de vivências e diálogos intergeracionais. Revista Extendere, v. 1, n. 2, 2014. 
Prevenção de cárie em crianças do Piauí: um relato de experiência

MENDONÇA, Iasmim Barreto et al. Extensão universitária em parceria com a sociedade. Caderno de Graduação-Ciências Humanas e Sociais-UNIT, v. 1, n. 2, p. 149155, 2013.

MORAES, Sandra Lúcia Dantas de et al. Impacto de uma experiência extensionista na formação universitária. Revista de Cirurgia e Traumatologia Buco-maxilo-facial, v. 16, n. 1, p. 39-44, 2016.

PEREIRA, Jaqueline Lopes et al. Considerações sobre interdisciplinaridade a partir de depoimentos de participantes da equipe de nutrição do projeto de extensão universitária" bandeira científica". Demetra: alimentação, nutrição \& saúde, v. 8, n. 2, p. 183-195, 2013.

PEREIRA, Stela Márcia et al. Extensão universitária e trabalho voluntário na formação do acadêmico em Odontologia. Arquivos em Odontologia, v. 47, n. 2, p. 95-103, 2011.

RODRIGUES, Andréia Lilian Lima et al. Contribuições da extensão universitária na sociedade. Caderno de Graduação-Ciências Humanas e Sociais-UNIT, v. 1, n. 2, p. 141 $148,2013$.

VALARELLI, Fabrício Pinelliet al. Importância dos programas de educação e motivação para saúde bucal em escolas: relato de experiência. Odontologia Clínico-Científica (Online), v. 10, n. 2, p. 173-176, 2011.

WARMLING, Alessandra M. Ferreira et al. Contribuições das atividades complementares na formação. Revista da ABENO, v. 12, n. 2, p. 190-197, 2012.

Recebido em: 06/11/2017

Aceito em: 03/07/2018 